\title{
Skin care during the menopause period: noninvasive procedures of beauty studies
}

\author{
Joanna Herman ${ }^{1}$, Magdalena Rost-Roszkowska ${ }^{1,2}$, Urszula Skotnicka-Graca ${ }^{1,3}$ \\ ${ }^{1}$ Silesian Medical College, Katowice, Poland \\ Head of College: Prof. Jacek Starzewski MD, PhD \\ ${ }^{2}$ Department of Animal Histology and Embryology, University of Silesia, Katowice, Poland \\ Head of Department: Piotr Świątek MD, PhD \\ ${ }^{3}$ Surgery Nursery Department, General Surgery and Multi-organ Trauma Chair, Silesian Medical University, Katowice, Poland \\ Head of Department: Eugeniusz Majewski MD, PhD
}

Postep Derm Alergol 2013; XXX, 6: 388-395

DOI: 10.5114/pdia.2013.39430

\begin{abstract}
Ageing is a resultant of two processes, including genetically encoded changes in an organism and modifications caused by a negative external environment impact. In the histological aspect, the skin ageing, due to endogenous factors and hormonal changes shows: excessive dryness, Malpighian layer thinning, microcirculation disorders, collagenic or elastin fiber degradation and simultaneous glycation, decreased speed of sebum and perspiration secretion. It is said that skin is a functional picture of the organism and endocrinological system. Any hormone concentration ups and downs may improve its appearance or significantly worsen its condition as well as it may lead to occurrence of dermatological changes. In adult women, the ageing process changes its significance step by step. Despite the passage of time, women want to feel good inside their skins. The adult skin is more requiring and it needs special care, often using a cosmetic apparatus. For better effect and permanent revitalization of the ageing skin, it is recommended to apply properly selected home-use cosmetic preparations. A holistic approach makes it possible to reach the skin density and thickness increase, wrinkles shallowing, humidity and resilience improvement and also recovery of the proper face oval.
\end{abstract}

Key words: menopause, skin ageing, hormones, noninvasive cosmetic procedures, mature skin care at home.

\section{Introduction}

Not long ago the menopause was a "taboo", connected with a decadent life phase. Lack of a reasonable approach to the menopause period prophylactics makes women feel a large discomfort during this period and exposes them to the occurrence of the dangerous illness. Fortunately, the "prime age" women are more and more aware and it allows them to see also positive aspects connected with the menopause period. External symptoms of the skin ageing result from complicated longtime processes occurring in it or arise due to a decrease in biological activity of its cells. In order to keep the ageing skin in good condition, it is recommended to provide professional care in beauty parlors and apply properly selected cosmetics for care at home.

\begin{abstract}
Ageing process theories
Population ageing is an unavoidable demographic process. Due to improvement of social conditions and better access to medical care the average lifetime is still longer and longer. The ageing processes have beenbanalyzed for years by scientists, alchemists, clergy, doctors or philosophers. The ageing secret still remains undiscovered. However, there are many theories or hypotheses, which try to explain how this process occurs at the cell, tissue or organ levels. The Hayflick limit theory of ageing assumes that each cell has a defined "lifetime" depending on the number, which it can divide, and the division number is, in turn, connected with the decreasing, in the line with the age, volume of the telomerase enzymes, thanks to which telomeres after their cut-off, after each division, are added to chromosomes. Other theories show the changes con-
\end{abstract}

Address for correspondence: Magdalena Rost-Roszkowska PhD, Department of Animal Histology and Embryology, University of Silesia, 9 Bankowa St, 40-007 Katowice, Poland, phone: + 483235913 76, mobile: +48 603708098 ,

e-mail: magdalena.rost_roszkowska@swsm.pl

Received: 13.02.2013, accepted: 22.05.2013. 
nected with composition of the albuminous or lipidous cell membranes (membrane theory), decreasing number and activity of mitochondria (mitochondrial decline theory), or increased degradation of proteins (protein disorder theory). For sure, the physiological ageing occurs when the cell atrophy processes (cell death) prevail over their division or regeneration. This applies to both internal human organs and the skin $[1,2]$.

\section{Menopause}

The menopause and peri-menopausal period is a specific time in a woman's life. Medicine defines the menopause as appearance of the last menorrhea, after which it does not occur for about 1 year. It is impossible to say unmistakably what is the age when a given woman comes into climacterium because it depends on many factors (e.g. multiparity, hormonal therapy, life style, genetic conditions or diet). It is estimated that 5 years, on average, before the menopause the so-called perimenopause starts, during which menstruation disorders or hormone concentration changes occur. Professional medical literature assumes that the age of ca. 50 years is the time when women come into a menopause period. No menstruation is responsible for occurrence of especially arduous, so-called "fall-out signs", i.e. so-called climacterium syndrome (including heat blow, palpitation, fear attacks, depression inclination, drenching sweats, insomnia, concentration troubles) [3-9].

Ovary hypofunction often leads to changes affecting the entire organism. The urogenital atrophy develops due to decreased production of cells inside the vagina and estrogen receptors atrophy inside the urethra. Decrease in the muscle mass and collagen stiffening cause decrease in the joints or muscles efficiency. The characteristic symptom occurring together with muscle relaxation is the genital organ prolapse, where the preservative therapy is recommended (at the first phase of the illness) or surgery. Together with the age, the risk of circulatory system illness increases, which results in an increase in the LDL value or in the blood clotting factors. During first years after menopause, the highest drop of the spongy bone tissue mineralization occurs. The osteoporosis is observed if the bone tissue resorption process prevails over the renovation one. The post-menopausal osteoporosis is a complicated illness process, depending on genetic, nutrition or hormonal factors. Mature women are exposed, most often, to fractures of vertebrae, ribs, pelvis, femoral, antebrachium or carpal bones. Prophylactic application of a calcium-rich diet and additional supplementing with D vitamin, active life-style and use of the substitute hormonal therapy efficiently protects them against unwanted bone fractures. The perimenopausal obesity is connected with a menopausal metabolic syndrome, which decreases tissue sensibility for insulin action (insulin resistance). This process may be responsible for occurrence of the type 2 diabetes, which very often occurs in mature people who do not observe diet requirements and have an inactive life-style. Also together with an age, the oncologic disease occurrence hazard grows. The most often neoplasms occurring in peri-menopausal women are: cancer of the breast, ovaries, uterus body or large intestine [10-15].

\section{Characteristics of mature skin in the endocrinological aspect}

Contrary to the young and healthy skin, the mature one is characterized by atrophic or pigmentation changes, telangiectasias or deep wrinkles. On the external skin surface, there are clear signs of damage due to many hormonal, genetic or environmental factors seen. The skin ageing process starts at the age of 25 (first mimic wrinkles appear then) and visible ageing symptoms may be observed at the age of about 35 years. Wrinkles are caused by the loss of the skin flexibility and firmness, inadequate humidity, stress, unhygienic life-style, endo- or exogenic factors. Around 50 years of age, due to endocrinological disorders, epidermal water binding function is impaired, which causes fixation of static wrinkles and it leads to permanent damage of the skin lipid cement. Atrophic changes that lead to a decrease in muscle volume and degradation of hypodermic tissue are characteristic of the mature skin. Consequently total atrophy, translocation or retention of the face fatty tissue may occur. The ageing process occurs in all the skin layers, and it also relates to the atrophic changes within the appendage areas (weak perfusion of hair follicles or nail beds). The endogenous ageing causes gradual degradation of fibroblasts, blood vessels, natural moisturizing factor (NMF), melanocytes or Langerhans cells. All these disturbances lead to the atrophic changes. The key factors here are the changes meaning epidermis thinning (keratinocyte proliferation inhibition), limiting of the skin flexibility and also progressive fatty tissue regression (e.g. "pouches under the eyes"). Atrophic changes appearing idiopathically, may be congenital or acquired ones and they also often coexist with different dermatoses. The endogenic ageing affects the facial features. We can observe the lowered nose tip, eyebrows and cheeks on the mature woman's face. The bone tissue atrophy, best visible in the mouth area, is also characteristic here. When ageing, nervous fiber endings are also subject to degeneration, which is sensed as sudden skin tingling. Moreover, the mature skin is sensible and it shows a tendency to papillae, acne rosacea, hirsutism-type changes, and also to aggravation of chronic dermatoses [16-23].

First of all the hormones are responsible for the skin condition, affecting the ageing process speed, causing different skin defects and affecting the course of chronic dermatoses. Hormonal skin ageing co-exists with the chronologic and photo ageing. Amongst many different 
hormones, the main ones responsible for the ageing are the sexual ones. It appears that the skin is the so-called "estrogen and androgen receptors map". The hormone largest clusters are located on the skin surface of the face, lower limbs and within the genital organ area. In the histological picture, such changes occur in the epidermis, skin and subdermal tissue [2, 24].

At the epidermis and skin levels, the sexual hormones limit cell proliferation resulting in the epidermis and vascular bed atrophy. A decreased number of proteins anchoring in the ageing skin leads to the skin-epidermis border being blurred. Reduced activity of collagen and elastin fibers decreases the glucose-amine-glucans concentration, which results in the process of the collagen and elastin fibers devastation and consequently the elastosis. During the ageing process, the collagen loses its physical and chemical features, its turgescence ability decreases, the hydroxyproline concentration in it grows and its calcium binding ability increases. Collagen density during the post-menopausal period drops by $2 \%$ annually on average. Lack of the proper blood circulation causes a decrease in the melanocyte and Langerhans cells number in the epidermis. Skin becomes less resistant to external or internal factors and its permeability increases [24-28].

The hypodermic tissue also suffers from the sexual hormones value ups and downs. Impairment of peroxisomes and the so-called PPAR receptors causes a decrease in the adipocytes activity. This process results in decomposition or atrophy of the fatty tissue. Characteristic changes occur in the area of the superciliary arch, orbits, temples and cheek bones. The jaw, nasolabial folds and chin become also the fatty tissue reservoir [27, 29, 30].

The ageing process is connected with hormonal disorders during the menopause and post-menopause period and is also related to chronic dermatoses. Some dermatoses due to hypo-ovarism may have a milder course or may be subject to aggravation.

\section{Renaissance of modern cosmetology for senior women}

Systematic visits of 50+ women to beauty parlors, not long ago, were a rarity, because it was common to "accept the passage of time". Today mature women are aware of their mature beauty, are open to the "aging well" trend (anti-ageing care based on acceptance of time passage) and more and more willing to use homecare cosmetics, live actively and also expect high skills of the beauty parlor personnel [31, 32].

\section{Beauty parlors' non-invasive procedures for menopausal women}

Timeless Hippocrates' saying: "better prevent than cure", is still up-to-date in the aspect of the mature skin care. Currently, the majority of beauty parlors offer a wide range of cosmetic services tailored to the mature women's needs. The proposed procedures are aimed at deceleration of the ageing process by activation of the natural skin renovation and regeneration process. Due to stimulation of collagen or elastin fibres and improvement of a skin microcirculation, the skin becomes more resistant to the action of endo- or exogenic factors. In order to obtain satisfactory effects, a given procedure or the joint therapy series should be performed. A cosmetologist who promotes health and beauty, takes care of the mature skin by propagation of a holistic approach, which besides the special cosmetic procedures, recommends also proper diet, supplementation of vitamins, micro- or macro-elements, hyaluronic acid, as well as active and hygienic life-style. Meeting these recommendations results in stimulation of tissue metabolism, enables self-regeneration and proper cell oxygenation, which positively affects the entire organism [31, 32].

Massage and its properties are known from time immemorial. First notes about the massage can be found in the ancient Egypt, Greece or Rome history. The cosmetic massage cradle was undoubtedly the ancient Egypt. In Greek "massein" means to knead. Massage means an elastic tissue deformation, while keeping the organism passive, and tissues are stimulated mechanically. In the beauty parlors, the massage has been very popular for years. This procedure improves the blood and lymph circulation, exfoliates the epidermis corneal layer corneocytes, cleans skin pores, excites fibroblast synthesis and excellently prepares the skin for receipt of active substances. Traditional cosmetic massage consists of the five consecutive techniques: stroking, rubbing, pressing, patting, vibrating and the procedure ends with delicate final stroking. On the dry, flabby skin, with visible ageing signs, the massage is provided using strongly moisturizing preparations, which during the procedure can deeply penetrate tissues. For better effects of the active substances, if no counter-indication exists, massage may be carried out under the vapozone. When massaging the mature skin, most of time should be used for the stroking and patting phases, because these techniques positively affect the collagen synthesis as well as the nervous system. The rubbing technique should be used with low intensity, because the mature skin is prone to flabbiness and the connective tissue stretching [33-36].

More and more often mature women are offered to have a reflexology face massage with an anti-wrinkle and relaxation effect. The reflexology face massage, contrary to the traditional classic massage, means stimulation of the acupuncture zones and points. This procedure activates one of the brain centers, amygdala nucleus, which affects the human lymphatic system causing elimination of nervous tension and helping removal of the negative metabolism products. Moreover, this procedure efficiently counteracts creation of new wrinkles, facilitates blood and lymph flow (prevents swelling), makes the skin ex- 
cellently firm, corrects the eye and mouth corners and activates regeneration processes (e.g. after a surgery) $[37,38]$.

Another massage type is lymphatic drainage, which removes lymphostasis, i.e. it acts as drainage. The masseuse acts on tissues by pressure with simultaneous transfer of the lymph towards the lymph nodes. The procedure is made using a stroking technique plus spherical rubbing of the regional lymph-node areas. Next the lymphatic massage (lymph drainage) is provided to the regional lymph nodes. After this procedure, the skin is duly regenerated and vitalized and swelling is decreased [34, 39].

In order to revitalize the mature skin, beauty parlors use chemical peeling more and more frequently. First natural peelings were known already in the Pharaoh times. In the ancient Egypt a "white face" (immaculately light skin) was cultivated, because it was a sign of wealth and social status. The procedures causing controlled epidermis damage have evolved for centuries. For revitalization of a mature skin, today beauty parlors most frequently use fruit acids (hydroxy acids), polyhydroxy acids or cholic acid [40, 41].

The hydroxy acids called also "fruit acids" cause keratolytic action to epidermis and the papillary skin layer. The therapeutic effect means an increase in the cell metabolism, activation of glucose-amino-glucans, which ensures maintenance of a proper moisturizing level. Activation of fibroblasts with simultaneous inhibition of collagenosis, enables regeneration of elastin fibres and increase the collagen network density. The fruit acids, most often used in cosmetics, are: lactic, glycolic, citric, malic, mandelic or tartaric acids. The most conditioning acids, when revitalizing a mature skin, are the mandelic or glycolic ones. The glycolic acid extracted from sugar cane has the smallest particles from among all the acids, thus it can easily penetrate any epidermis layer. When penetrating the skin it loosens intra-cell connections, interlocks activity of enzymes responsible for cohesion of corneocytes, carefully peels epidermis, improves moisturizing of dry skin, eliminates free radicals and helps epidermis permeability and its penetration by depigmentation elements or vitamins. Moreover, it stimulates fibroblasts or glucose-amino-glucans (GAG), regenerates the skin, clears up scars or melanosis, makes wrinkles shallow, cleans and increases tissue tension (makes it more firm). The mandelic acid is obtained from bitter almonds, peach or cherry stones and contrary to the glycolic acid, it is characterized by large particles and therefore it poorly penetrates the skin structure. It has strong, comparable to antibiotics, anti-bacteria action (shows efficiency against: Staphylococcus aureus, Bacillus proteus, Escherichia coli and Aerobacter aerogenes). The mandelic peeling is recommended for the sensible skin therapy, with telangiectasia and with symptoms of chronological or photo ageing. Moreover, it clears up the skin surface melanosis (e.g. chloasma, senile lentigines). It is very well tolerated by the skin, cause no sunbeam hyperergia, may be applied in patients with any phototype without any melanosis hazard $[42,43]$.

The other group of compounds used as chemical peelings are polyhydroxy acids, which in comparison with hydroxy acids, poorly penetrate the tissues. The polyhydroxy acid therapy cause no irritation, its action is strongly moisturizing and antiradical one. An additional advantage of these acids is their action that seals up blood vessels and they are extraordinarily well tolerated by the skin. Therefore it is perfectly suitable for the whelk skin therapy, very often occurring in women during the peri-menopausal period [45].

The other acid proposed to mature women is the cholic (5-hydroxy-2-hydroxymethyl-4-pyrone) acid, which efficiently interlocks excessive production of melanin (tyrosinase inhibitor) ensuring a good effect of the local bleaching of hyperpigmentation focuses. The cosmetic cholic acid is extracted from the Aspergillus type fungus, which grow on Japan maize or from the Penicillium type fungus [44].

Other procedures proposed to women during or after menopause are the micro-dermabrasion ones, used for controlled, mechanical epidermis micro-peeling. The procedure has multi-directional effects which lead not only to improvement of the general skin condition, but also significantly reduce skin melanosis and wrinkles. Regular micro-dermabrasion procedures remove scars, make wrinkles shallow, stimulate tissue regeneration, counteracts loss of collagen, fibres firmness and elasticity, and prepares skin for introduction of active substances. The histological picture confirms thickening of the skin, which additionally enforces its protective function against external factors. For the mature skin that is characterized by intensified sensibility and telangiectasia inclination it is especially recommended to perform micro-dermabrasion based on physiological salt and oxygen, i.e. so-called touchless oxybrasion. This procedure guarantees exact skin cleaning, good moisturizing, blood vessels shrinking, stimulation of fibroblasts, and it is also a completely painless and non-invasive procedure [2, 46, 47].

For several years the radio-wave emitting devices have been used in beauty parlors to improve skin firmness and tension. It results from production of a high frequency alternative current, which is then converted to electromagnetic power. The cosmetic apparatus uses the waves with frequencies from $3 \mathrm{MHz}$ to $6 \mathrm{MHz}$. The lower HF current frequency the deeper tissue penetration. Emission of the radio waves makes it possible to obtain the thermolysis effect on the level of skin and subdermal tissue. The radio-wave emitters heat the tissue up to the temperature of $45-55^{\circ} \mathrm{C}$. This process affects denaturation of collagen fibers with their simultaneous shrinking and it activates tissue metabolism and helps reconstruct damaged tissue caused by degeneration processes. In 
2002, the US Food and Drug Administration (FDA) did admit the radio-wave emitting apparatus as the efficient therapy fighting the face wrinkles. After a series of procedures, the skin elasticity increases, wrinkles are filled, face contour and cheeks are shaped. This means that the radio waves, besides external action, helps also to reconstruct the tissue damaged due to ageing. The radio-wave emitters have also a wider action spectrum, and namely their excellent use gives positive results also in the cellulite therapy and in fighting of flabby skin on arms, belly or buttocks. The final effect of the tissue structure firming, tension and reconstruction is visible within several months after the procedure. Proper selection of the temperature and the penetration depth is possible thanks to different procedure techniques. There are monopolar, bipolar or unipolar techniques. Modern devices that emit radio waves are the Thermage systems. The procedure is performed using the frequency about $6 \mathrm{MHz}$ using the monopolar method. Biological effects are the same as those of traditional radio-wave emitters. The Thermage system novelty is the procedure itself. A special working head produces the thermolysis effect, penetrates tissues to the depth of 3-4 mm, while the external skin surface is cooled with a cryogenic agent. Both the traditional radio waves and the Thermage system are recommended for the therapy of skin having visible ageing signs (wrinkles, descent eyelids, flabby cheeks and chin) as so called noninvasive skin lifting [32, 46-48].

The DC current emitting devices are mainly used for regeneration of a mature skin. Electric current has been used for years as a safe alternative to plastic surgery procedures. Galvanization means application of special electrodes on the wet skin. Due to electric current intensity, ions are put into movement and they start to move inside the tissue, which increases the histamine concentration. It results in expansion of blood vessels and stimulation of the nervous system. These procedures are recommended in the atrophic skin therapy in order to increase muscle tension, improve the skin microcirculation and proper cell oxygenation. Another procedure using the DC current is the iontophoresis enabling active substances to enter tissues [2, 32, 49, 50].

Mature women who, due to their age, lost their face muscle elasticity and firmness, are advised to use the electrostimulation procedures, which are an excellent alternative to invasive medical procedures. The low-frequency pulse currents stimulate the cell metabolism, which efficiently reduces wrinkles, swelling, fatty tissue excess and also increases the muscle fiber contractility [31, 32, 47].

Ultrasounds are also used for fighting the ageing symptoms. The ultrasound waves are mechanical, elastic vibrations the frequency of which exceeds the human audibility $(16 \mathrm{kHz})$ [51]. The biochemical processes occurring in tissues due to ultrasounds result from the polymerization and depolymerization. As a result of po- lymerization, individual particles join and form a larger molecule. Additionally, the ultrasound wave regenerates tissues because it stimulates synthesis of many proteins. The depolymerization process decreases the particles' mass and elastic properties, which enables better penetration of fluid active substances. Ultrasound waves are responsible for proper tissue metabolism and detoxification. The cosmetic ultrasound emitting devices enable cavitation, iontophoresis or no needle mesotherapy. General therapeutic effects of the ultrasound wave, visible on a skin surface are: blood and lymph circulation stimulation, removal of wrinkles, swelling or pigmentation spots, normalization of the sebaceous glands activity, improvement of firmness and elasticity, better permeability of cell membranes, stimulation of enzymatic processes and anti-bacterial action. Ultrasonophoresis (sonophoresis) is the procedure using the ultrasound waves for introduction of active substances into the skin. Depending on the used preparation, the sonophoresis is applied in order to eliminate wrinkles, swelling or pigmentation spots, normalize the sebaceous glands activity, improve the face oval and reinforce blood vessels. The curative effect of sonophoresis is visible mainly on the cell level, where the cell membrane permeability growth and stimulation of enzymatic processes occurs. Moreover, stimulation of biologically active compounds occurs, tissue metabolism improves and cell oxygenation increases. The ultrasound vibrations are also used for skin cleaning as cavitation peeling with simultaneous micro-massage. It makes it possible to carry out a noninvasive cleaning procedure with simultaneous skin care and regeneration. The cavitation phenomenon causes production of gasfilled blisters that explode due to increased pressure. This procedure is carried out using a cosmetic apparatus equipped with a spatula and the interconnecting substance is a water solution. The spatula transfers vibration to skin the by forming microscopic blisters on it, which explode and smash the horny epidermis cells and remove all the impurities. The cavitation peeling improves the general skin condition and additionally fights bacteria. This procedure is recommended for removal of small pigmentation chromatosis or scars, shallowing of wrinkles or collagen stimulation. The cleaning procedure that uses the ultrasound waves may be carried out unaided or it may be an additional mature skin therapy element [31, 32, 47].

The needle mesotherapy is an innovative procedure meaning intradermal injections, connected with simultaneous administration of different lyophilic active substances directly to the points of cosmetic defect. First trials of introducing the mesotherapy with the cosmetic indications were performed in the 1970s. Currently, the needle mesotherapy is a popular, noninvasive procedure, which positively affects the condition of skin, subdermal tissue and hair. The effect of focus healing is also characteristic of this procedure, which increases the skin regen- 
eration process. This procedure is carried out by a manual or mechanical technique using a special pistol. The needle mesotherapy is currently also the most popular and safe method suitable for rejuvenation of skin of the external part of the palm or revitalization of the hairy head skin. The intradermotherapy improves the cell metabolism, stimulates collagen and elastin fibers, makes wrinkles shallow (filling effect), improves the skin firmness and tension and also it affects the tissue nutrition and regeneration. The additional advantage of this therapy is the focus healing effect, which arises after many micro-punctures. The so-called conditioning substances, which are inserted by such injections, are e.g. the organic silica, hyaluronic acid (HA), multi-vitamin complex, rutin extract, artichoke and yellow melilot extracts, phosphatidylcholine (lecithin), L-carnitine and caffeine. For better skin biostimulation effects, the so-called normothermia, i.e. proper tissue temperature should be ensured, which should be $36.8-37.2^{\circ} \mathrm{C}$ strengthening the physiological processes. The mesotherapy should be carried out as a series of procedures. At first, the procedure frequency should be higher (every 10-14 days), then it comes to the maintenance phase (every 4-6 months). An alternative to the needle intradermotherapy is no needle mesotherapy, based on the epidermis electroporation phenomenon. This procedure makes it possible to introduce active substances with larger particles to epidermis layers. The no needle mesotherapy causes no epidermis damage and it is a noninvasive method which stimulates cells' pinocytosis (substance absorption to the cell interior) thanks to which the active substances from cosmetic preparations retain in the skin up to 2 days after the procedure and there they are released gradually [2, 32, 46, 52, 53].

Chrysotherapy is connected with healing of different disorders using gold ( $\mathrm{Au}$ ). Advantages of this precious metal were appreciated already by Cleopatra who put the golden mask on her face every night, and also the Qing dynasty queen who did make a face massage using a golden roller. Zbigniew Nienacki wrote: "Gold opens all the gates and knocks weapon out of enemy's hands", thus the chrysotherapy has been used for centuries in the Chinese, Tibetan or Ayurvedic medicine. Gold has been to heal chronic joint inflammations, the nervous, osseous or circulation system disorders. This element strongly impacts the immune system, which improves the organism vitality and protective functions. Use of the gold in the mature skin therapy is a noninvasive and efficient stimulation procedure. The gold-based procedures affect collagen synthesis, significantly improve the epidermis moisturizing, delay the skin ageing process, activate migration of active substances into deeper skin layers and promote the transdermal organism cleaning. The cosmetic industry uses the micro-particles of 24-carat gold, which has anti-inflammatory properties, stabilizes pigmentation, lights up the skin, decreases the allergy risk and has an anti-wrinkle effect. The gold-use proce- dures may be carried out using a ready cosmetic preparations that include gold particles or by special apparatus equipped with golden heads (micro-currents) [46].

Cold therapy (cryotherapy) is one of the oldest methods used in the physiotherapy. As early as in ancient times Hippocrates did discover the beneficial properties of cold. Using the hypothermia (cooling-down) phenomenon, he decreased different type swellings and alleviated pain. Cryotherapy has been used in cosmetology for a short time, but obviously it will be its indispensable element in the nearest future. The cold causes a thermal shock by narrowing blood vessels and gradual slowing down of blood circulation and metabolism. It is a totally natural reaction, which is very short, and after a while, suddenly blood vessels widen, which results in congestion. The cryodestruction is commonly used for removal of particular dermatological changes. The cold therapy is more and more appreciated in beauty parlors. This technique is used e.g. to improve the comfort of the permanent make-up (Cryopigmentation) by limiting the bleeding and reddening of the procedure subject places. The anesthesia effect is obtained by cold acting on the free nervous endings existing in the skin receptors. The cosmetology novelty is the cryostimulation connected with the active components, called Cryolift. This procedure is recommended especially in the therapy of swelling, flabby skin of the face, belly or arms, melanosis (melanocytes are destroyed at the temperature of $-7^{\circ} \mathrm{C}$ ). Cosmetic cryotherapy leads to the so-called "vasomotor paradox", where the blood vessels are first shrunk and then, after releasing of chemical mediators, they are quickly loosened. This process makes it possible to introduce into the skin active substances in the form of protein, oligonucleotide or peptide particles and properly selected bio-pharmaceutical agents. The working head releases cold at the temperature of $-15^{\circ} \mathrm{C}$, which very efficiently removes swelling or melanosis and stimulates flabby tissue. The Cryodermie procedure acts stronger in a mature skin revitalization; that procedure uses cold at the temperature of $-50^{\circ} \mathrm{C}$ and strongly stimulates collagen and fights free radicals. After this procedure, the skin is well stretched, moistened, nourished, oxygenated, and wrinkles are less visible. The cosmetic cryotherapy also gives satisfactory firmness effects in the procedures relating to breast, upper or lower limbs and it is also used in the anti-wrinkle therapy as the cryopeeling [54-56].

Modern cosmetology looks for the most efficient methods fighting skin ageing. Acupuncture in a cosmetology uses medical techniques of the Far East. It is a good alternative to the plastic surgery or esthetic medicine procedures. The real renaissance of the acupuncture is currently witnessed in the USA and Japan, where it has more and more followers. This procedure means a precision puncture of particular meridians, thus activating bio-electric energy. The sympathetic or parasympathetic systems are activated during this procedure, which re- 
sults in the whole organism homeostasis. This process leads to improvement of dermal microcirculation, loosening of muscles and stimulation of fibroblasts. Skin regains its healthy coloration and seems to be well stretched. This procedure carried out on a mature skin (face, neck, décolletage, palms) fights wrinkles, and has revitalizing and lifting effects. The satisfactory effects are also obtained in the therapy of neurological disorders and in prophylactics of the menopause syndrome and insomnia. The punctures eliminate muscle tissue tension, nervous facial spasms or trismus. The cosmetic acupuncture efficiently fights swelling (due to lymphostasis), prevents the upper eyelid falling, improves a face oval and skin moisturizing level. Systematic procedures make it possible to decrease or correct wrinkles, especially at the eye or mouth area, and also deep nose-lips lines. Moreover, the acupuncture is widely used in healing many dermatoses and is recommended as a prophylactic procedure in order to alleviate the menopause symptoms [57-60].

\section{Mature skin prophylactic therapy at home}

There are a number of cosmetic products offered for the mature skin care at home. The cosmetic companies researches show that mature women predominantly use the make-up removing preparations or care creams. The current creams for mature women include several active components, which are well matched to particular skin types (e.g. dry, sensible or fatty one). It is very important for the active substances to keep their properties, therefore they are closed inside special nanosomes or liposomes. Due to fierce competition amongst the cosmetic companies, we can find in a small jar such innovations as e.g. peptide from the Asiatic snake venom, probiotics, resveratrol, RNA and DNA of vegetable origin, enriched with glacier water, etc. A large interest has been paid lately to cosmetics including the vegetable mast cell extracts closed in liposomes, which are obtained in the labs e.g. from alpine edelweiss, lilac, Uttwiler Spätlauber apple tree, Echinacea angustifolia or Buddleia davidii.

Special attention should be paid to cosmeceuticals, sold in pharmacies only. This is a group of modern cosmetics with care and healing properties, recommended for even very sensitive skin. Their rich formulae guarantee high efficiency and consumer satisfaction. The cosmeceuticals act multi-directionally because they excellently support healing of different dermatoses and also perfectly take care of the healthy skin. Modern cosmetics are made of high quality raw materials, mostly of natural origin. Ready cosmetic preparations include no artificial pigments, are odorless and the preservatives' quantity is reduced to a minimum, which limits the allergy risk. Biologically active substances in these cosmeceuticals are in a larger number and higher concentration than in the traditional cosmetics. An additional advantage of the pharmaceutical cosmetics is the fact that they include thermal waters, which thanks to oligo elements (sodium, potassium, silicone, selenium, zinc) positively affect the sensitive or irritated skin [2, 31, 46].

\section{Summary}

Senility is a natural process inherent in human genes. The skin ageing process is considerably affected by hormones and genetic or environmental factors. The following are typical of the mature skin - pigmentation changes, telangiectasias, wrinkles and atrophies that lead to decrease in the muscle volume and degradation of subdermal tissue. The ageing skin is sensitive and prone to form superficial flat seborrheic warts, characterized by corneous pseudocysts, which may be accompanied by pruritus and inflammatory status, acne rosacea, hirsutism-type changes, and also to aggravation of chronic skin diseases. The professional medical literature assumes the age of ca. 50 as that when women's menopause period commences. This period fosters occurrence of many disorders dangerous for health. Professional procedures carried out in beauty parlors are aimed to restore proper moisturizing and nutrition of skin, stimulate the fibroblast synthesis processes and enable regeneration and proper renovation at the cell level. Properly tailored home care is a prophylactic action aimed at deceleration of the skin ageing.

\section{References}

1. Hayflick L. Why and how we grow old [Polish]. Wydawnictwo Książka i Wiedza, Warsaw 1998.

2. Noszczyk M. Care and medical cosmetology [Polish]. Wydawnictwo Naukowe PZWL, Warsaw 2010.

3. Genazzani AR, Gambacciani M, Simoncini T. Menopause and aging, quality of life and sexuality. Climacteric 2007; 10: 88-96

4. Jagielska I, Grabiec M, Wolski B, et al. Frequency of depression symptoms during climacterium period in women during post-menopause [Polish]. Prz Menopauz 2007; 3: 140-4.

5. Pawlikowski M. Hormonal disorders [Polish]. Wydawnictwo Naukowe PZWL, Warsaw 2003.

6. Skałba P. Ginecological endocrynology [Polish]. Wydawnictwo Naukowe PZWL, Warsaw 2008.

7. Skrzypulec V, Drosdzol A, Ferensowicz J, et al. Evaluation of selected women's psychical and sexual life aspects in the perimenopausal [Polish]. Ginekol Prakt 2003; 11: 26-34.

8. Humeniuk E, Bojar I, Owoc A, et al. Psychosocial conditioning of depressive disorders in post-menopausal women. Ann Agric Environ Med 2011; 18: 441-5.

9. Żołnierczuk-Kieliszek D, Kulik DB, Jarosz MJ, et al. Quality of life in peri- and post-menopausal Polish women living in Lublin Province - differences between urban and rural dwellers. Ann Agric Environ Med 2012; 19: 129-33.

10. Albright F, Smith PH, Richardson AM. Postmenopausal osteoporosis: its clinical features. JAMA 1941; 116: 24-65.

11. Andryskowski G. Calcium supplementation after the menopause [Polish]. Prz Menopauz 2006; 5: 329-32.

12. Buchsbauma J. Menopase [Polish]. Wydawnictwo Naukowe PZWL, Warsaw 1989. 
13. Lapiere CM, Nusgens BV. The extracellular matrix and its regulation. Pathol Biol 1992; 8: 110-23.

14. Stetkiewicz T, Pertyński T. Osteoporosis diagnostics and therapy [Polish]. Prz Lek 2005; 4: 66-71.

15. Suzin J, Szubert M, Kowalczyk-Amico K. Osteoporosis - frequent problem in post-menopausal women [Polish]. Prz Menopauz 2009; 6: 320-3.

16. Kokot F. Water and electrolite or acid and alkali metabolism disorders [Polish]. Wydawnictwo Lekarskie PZWL, Warsaw 2001.

17. Pełka M, Broniarczyk-Dyła G. Menopause impact to the skin structure and physiological processes [Polish]. Prz Menopauz 2008; 6: 319-22.

18. Pieczyńska J, Fryśna J. Water and electrolyte disorder impact to skin [Polish]. Postępy w Kosmetologii 2009; 1: 16.

19. Trznadel-Budźko E, Rotsztejn H. Dermatological menopause aspects [Polish]. Prz Menopauz 2006; 6: 398-401.

20. Wojnowska D, Chodorowska G, Juszkiewicz-Borowiec M. Dry skin - pathogenesis, clinic and healing [Polish]. Postep Derm Alergol 2003; 2: 98-105.

21. Wolska H, Gliński W, Placek W. Common acne - pathogenesis and healing [Polish]. Przegl Dermatol 2007; 94: 171-8.

22. Polańska A, Dańczak-Pazdrowska A, Silny W, et al. Evaluation of selected skin barrier functions in atopic dermatitis in relation to the disease severity and pruritus. Postep Derm Alergol 2012; 29: 373-7.

23. Osmola-Mańkowska A, Silny W, Dańczak-Pazdrowska A, et al. The sun - our friend or foe? Ann Agric Environ Med 2012; 19: 805-9.

24. Wojnowska D, Juszkiewicz-Borowiec M, Chodorowska G. Menopause impact to skin ageing [Polish]. Postep Derm Alergol 2006; 3: 149-56.

25. Brincat M, Muscat Baron Y, Galea R. Estrogens and the skin. Climacteric 2005; 8: 110-83.

26. Brincat M, Versi E, Moniz CF, et al. Skin collagen changes in postmenopausal women, receiving different regiments of estrogen therapy. Obstet Gynecol 1987; 70: 123-7.

27. Rotsztejn $\mathrm{H}$. Skin ageing proceses increase in the menopause period [Polish]. Prz Menopauz 2004; 3: 63-5.

28. Verder-Sevrain S. Estrogens effect to skin ageing and potential role of selective estrogen receptor modulators. Climac teric 2007; 10: 289-97.

29. Donorfio LM. Fat distribution: a morphologic study of the ageing face. Dermatol Surg 2000; 26: 1107-12.

30. Hall G, Philips TJ. Estrogen and skin: the effects of estrogen, menopause, and hormone replacement therapy on a skin. Jm Acad Dermatol 2005; 53: 555-68.

31. Dylewska-Grzelakowska J. Applied cosmetics [Polish]. Wydawnictwo WSiP, Warsaw 2007.

32. Kasprzak W, Mańkowska A. Physiotherapy in cosmetology and esthetic medicine [Polish]. Wydawnictwo Naukowe PZWL, Warsaw 2010

33. Magiera L. Massage history outline [Polish]. Wydawnictwo BIO-STYL, Kraków 2007.

34. Magiera L. Massage in cosmetics and biological renewal [Polish]. Wydawnictwo BIO-STYL, Kraków 2007.

35. Mehta K, Mehta N. Face lifting massage [Polish]. Wydawnictwo Klub Dla Ciebie, Warsaw 2006.

36. Szczotka P, Mikuła E. Contemporary massage [Polish]. Wydawnictwo BODY WORK, Poznań 1998.

37. Kasperczyk T, Kmak S. Point massage and other reflexotherapy methods [Polish]. Wydawnictwo Kasper, Kraków 1998; $1-216$.
38. Lipska K. Reflexological anti-wrinkle massage [Polish]. Cabines 2010; 40: 6-7.

39. Földi M, Strö enreuther R. Manual lymphatic drainage outlines [Polish]. Wydawnictwo Elsevier Urban \& Partner, Wrocław 2005

40. Brody HJ. Peeling and skin resurfacing. Czelej, Warsaw 2001.

41. Gomolińska A. Exfoliate therapies [Polish]. Les nouvelles esthetiques 2009; 5: 16-9.

42. Broniarczyk-Dyła G, Wawrzycka-Kaflik A, Prusińska-Brałoś M et al. Pharmacological effect of chemical compounds used for chemical peeling [Polish]. Dermatol Estet 2004; 1: 19-23.

43. Woźniak M. Alfa-hydroxyl acids applied in dermatology or care and prophylactic cosmetology [Polish]. Dermatol Estet 2010; 2: 118-23.

44. Edison BL, Green BA, Wildnauer RH, et al. Comparison of anti-ageing multi-hydroxyl and alfa-hydroxyl acids [Polish]. Dermatol Estet 2004; 6: 341-6.

45. Martini MC. Skin cosmetology and pharmacology [Polish]. Wydawnictwo Lekarskie PZWL, Warsaw 2006.

46. Jaroszewska B, Korabiewska I. Contemporary cosmetology [Polish]. Wydawnictwo ATENA, Warszawa 2010.

47. Kasprzak W, Mańkowska A. Physiotherapy, healt-resort medicine and SPA [Polish]. Wydawnictwo Naukowe PZWL, Warsaw 2008.

48. Pisula-Lewandowska A. Radio waves prolong the youth [Polish]. Kosmetyka i Kosmetologia 2008; 4: 10-2.

49. Kiełczyńska-Czajka H. Physiotherapy in cosmetics [Polish]. Wydawnictwo Spółdzielcze, Warsaw 1982.

50. Mika T, Kasprzak W. Physiotherapy [Polish]. Wydawnictwo Naukowe PZWL, Warsaw 2006.

51. Polańska A, Dańczak-Pazdrowska A, Silny W, et al. High-frequency ultrasonography in monitoring the effects of treatment of selected dermatoses. Postep Derm Alergol 2011; 28: 255-60.

52. Adamski Z, Kaszuba A. Dermatology for cosmetologists [Polish]. Wydawnictwo Naukowe Uniwersytetu Medycznego im. Karola Marcinkowskiego w Poznaniu, Poznań 2008.

53. Broniarczyk-Dyła G, Tazbir M. Application of mezotherapy in dermatological therapy [Polish]. Przegl Dermatol 2009; 96: 121-5.

54. Chicheł A, Skowronek J. Modern healing of skin carcinoma - dermatology, surgery or radiotherapy? Contem Onkol (Poznań) 2005; 9: 429-35.

55. Gabryś MS, Popiel A. Cryotherapy in medicine [Polish]. Wydawnictwo Elsevier Urban \& Partner, Wrocław 2003.

56. Ignaszewska-Kuhbauch J. Wellness cryotherapy [Polish]. Beauty Forum Poland 2010; 4: 44-6.

57. Byambasuren-Federowska S, Federowski M. East medicine secrets [Polish]. Wydawnictwo ADAM, Warsaw 2007.

58. Garnuszewski Z. Acupuncture in contemporary medicine [Polish]. Wydawnictwo AMBER, Warsaw 1997.

59. Garnuszewski Z. Acupuncture renaissance [Polish]. Wydawnictwo Sport i Turystyka, Warsaw 1988.

60. Maczeret E, Samosiuk I. Acupuncture and other reflexotherapy methods. Wydawnictwo Naukowe PZWL, Warsaw 1992. 